\title{
Assessment of small-scale variability of rainfall and multi-satellite precipitation estimates using measurements from a dense rain gauge network in Southeast India
}

\author{
K. Sunilkumar, T. Narayana Rao, and S. Satheeshkumar \\ National Atmospheric Research Laboratory, Clouds and Convective Systems Group, Gadanki, India \\ Correspondence to: T. Narayana Rao (tnrao@narl.gov.in)
}

Received: 9 September 2015 - Published in Hydrol. Earth Syst. Sci. Discuss.: 13 October 2015

Revised: 18 February 2016 - Accepted: 6 April 2016 - Published: 4 May 2016

\begin{abstract}
This paper describes the establishment of a dense rain gauge network and small-scale variability in rain events (both in space and time) over a complex hilly terrain in Southeast India. Three years of high-resolution gauge measurements are used to validate 3-hourly rainfall and subdaily variations of four widely used multi-satellite precipitation estimates (MPEs). The network, established as part of the Megha-Tropiques validation program, consists of 36 rain gauges arranged in a near-square grid area of $50 \mathrm{~km} \times 50 \mathrm{~km}$ with an intergauge distance of $6-12 \mathrm{~km}$. Morphological features of rainfall in two principal rainy seasons (southwest monsoon, SWM, and northeast monsoon, NEM) show marked differences. The NEM rainfall exhibits significant spatial variability and most of the rainfall is associated with large-scale/long-lived systems (during wet spells), whereas the contribution from small-scale/short-lived systems is considerable during the SWM. Rain events with longer duration and copious rainfall are seen mostly in the western quadrants (a quadrant is $1 / 4$ of the study region) in the SWM and northern quadrants in the NEM, indicating complex spatial variability within the study region. The diurnal cycle also exhibits large spatial and seasonal variability with larger diurnal amplitudes at all the gauge locations (except for 1) during the SWM and smaller and insignificant diurnal amplitudes at many gauge locations during the NEM. On average, the diurnal amplitudes are a factor of 2 larger in the SWM than in the NEM. The $24 \mathrm{~h}$ harmonic explains about $70 \%$ of total variance in the SWM and only $\sim 30 \%$ in the NEM. During the SWM, the rainfall peak is observed between 20:00 and 02:00 IST (Indian Standard Time) and is attributed to the propagating systems from the west coast during active monsoon spells. Correlograms with different temporal integra-
\end{abstract}

tions of rainfall data $(1,3,12,24 \mathrm{~h})$ show an increase in the spatial correlation with temporal integration, but the correlation remains nearly the same after $12 \mathrm{~h}$ of integration in both monsoon seasons. The $1 \mathrm{~h}$ resolution data show the steepest reduction in correlation with intergauge distance and the correlation becomes insignificant after $\sim 30 \mathrm{~km}$ in both monsoon seasons.

Validation of high-resolution rainfall estimates from various MPEs against the gauge rainfall data indicates that all MPEs underestimate the light and heavy rain. The MPEs exhibit good detection skills of rain at both 3 and $24 \mathrm{~h}$ resolutions; however, considerable improvement is observed at $24 \mathrm{~h}$ resolution. Among the different MPEs investigated, the Climate Prediction Centre morphing technique (CMORPH) performs better at 3-hourly resolution in both monsoons. The performance of Tropical Rainfall Measuring Mission (TRMM) multi-satellite precipitation analysis (TMPA) is much better at daily resolution than at 3-hourly, as evidenced by better statistical metrics than the other MPEs. All MPEs captured the basic shape of the diurnal cycle and the amplitude quite well, but failed to reproduce the weak/insignificant diurnal cycle in the NEM.

\section{Introduction}

Precipitation is ranked among the most variable meteorological parameters in the Earth's climate system. It is also the most important parameter in the water and energy cycles (Levizzani et al., 2007; Kucera et al., 2013). Understanding and quantification of the variability of precipitation is im- 
portant not only for management decisions, but also to unravel the underlying processes governing the formation of precipitation and its variability. The density of rain gauges in many operational networks is often too poor to capture the small-scale (both in space and time) variability of rainfall (Habib et al., 2009). Research networks with a high density of gauges, but covering a limited area, are becoming increasingly popular to understand the sub-grid and sub-daily scale variability of rainfall. Measurements from such networks are also useful for the validation of precipitation estimates from microwave radars and imagers (Krajewski et al., 2003; Habib et al., 2012; Tokay et al., 2014; Dzotsi et al., 2014; Chen et al., 2015). The complexity in small-scale variability of rainfall increases in hilly terrain (Zängl, 2007; $\mathrm{Li}$ et al., 2014). The rainfall often becomes inhomogeneous due to topographic influence and is at times highly localized, resulting in large errors in the retrieved precipitation by passive/active remote sensors due to non-uniform beam-filling of precipitation within the satellite or radar pixel (Tokay and Ozturk, 2012). In order to understand the physical processes responsible for such variability, several studies examined the dependency of rainfall spatial variability (in terms of correlation distance, $d_{o}$ ) on rainfall regimes (Krajewski et al., 2003), seasons, spatial and temporal aggregation of data (Krajewski et al., 2003; Villarini et al., 2008; Luini and Capsoni, 2012; Chen et al., 2015; Prat and Nelson, 2015), sample size and extreme rain events (Habib et al., 2001) and geographical features like topography ( $\mathrm{Li}$ et al., 2014). Proper quantification of spatial correlation distance mitigates the uncertainty in the upscaling of rainfall from point-to-areal and also helps in designing rain gauge networks (Bras and RodriguezIturbe, 1993; Villarini et al., 2008).

At present, only a few dense research gauge networks are operational worldwide. Moreover, the gauge locations in operational networks are mostly confined to well-developed and easily accessible locations. This leaves large spatial data gaps in critically important areas due to the unavailability of gauges (over open oceans and remote locations). Furthermore, timely dissemination of precipitation data to concerned authorities is another critical issue. Near real-time high-quality precipitation measurements are vital for several weather and hydrological forecasting applications, e.g., flash flood forecasting and monitoring ( $\mathrm{Li}$ et al., 2009; Kidd et al., 2009). Satellite remote sensing is capable of measuring near real-time high-resolution (both in space and time) precipitation on a global scale, including oceans and complex terrain, where in situ precipitation measurements are missing (Wang et al., 2009). Recently, several merged satellite products have been developed by effective integration of relatively accurate active and passive microwave and high-temporal sampling infrared (IR) measurements. These multi-satellite precipitation estimates (MPEs) are becoming increasingly popular and several such products are now available providing high-resolution precipitation on near real time. They include, among others, the Climate Prediction Centre (CPC) morph- ing technique (CMORPH; Joyce et al., 2004), TRMM multisatellite precipitation analysis (TMPA; Huffman et al., 2007), Global satellite mapping of precipitation (GSMaP; Kubota et al., 2007; Aonashi et al., 2009) and Precipitation estimation from remotely sensed information using artificial neural networks (PERSIANN; Hsu et al., 1997; Sorooshian et al., 2000). Details of these MPEs, including their spatial and temporal resolutions and the input data used to generate them, are given in Table 1. However, several sources of uncertainties, including sensor inaccuracies, retrieval algorithms, not fully understood physical processes and beamfilling factors, limit the accuracy of MPEs (Levizzani et al., 2007). Therefore, validation of high-resolution MPEs and quantification of their errors are essential before utilizing them further for operational or research applications. Thus far, a great deal of effort has been put into evaluating the MPEs in different climatic conditions (Global Adler et al. (2001); Turk et al. (2008); Australia, United States of America (USA) and northwestern Europe - Ebert et al. (2007); Africa and South America - Dinku et al. (2010); India - Prakash et al. (2014); Sunilkumar et al. (2015); Iran Ghajarnia et al. (2015); China - Chen et al. (2015), and references therein) and seasons (Tian et al., 2007; Kidd et al., 2012; Sunilkumar et al., 2015). Though several studies exist on the evaluation of monthly to seasonal rainfall in the literature, only a few studies focused on validating the rainfall at daily and sub-daily scales (Sapiano and Arkin, 2009; Sohn et al., 2010; Habib et al., 2012; Kidd et al., 2012; Mehran and AghaKouchak, 2014).

The sub-daily evaluation of five MPEs over the USA and Pacific Ocean indicates strong performance dependence of MPEs on the region and season, i.e., overestimates warm season rainfall over the USA and underestimates it over the tropical Pacific Ocean (Sapiano and Arkin, 2009). They also noted that all MPEs precisely resolved the diurnal cycle of precipitation. By contrast, Sohn et al. (2010) have noted the underestimation of the amplitude of the diurnal cycle by CMORPH, PERSIANN and National Research Laboratory blended (NRL-blended) precipitation products over South Korea. The observed biases and random errors are found to be large at the highest resolution (event and hourly scale), but reduce to smaller values when the evaluations are carried out over the entire study period or when the data are aggregated in space and time (Habib et al., 2012). The performance evaluation of various MPEs and reanalysis precipitation products over northwestern Europe reveals a strong seasonal cycle in bias, false alarm ratio and probability of detection (Kidd et al., 2012). A detailed study on the detection capability of intense rainfall by various MPEs using a dense network of rain gauges reveals that none of the high-resolution ( $3 \mathrm{~h}$ ) MPEs are ideal for detecting intense precipitation rates (Mehran and AghaKouchak, 2014).

The above studies clearly elucidated that the error characteristics obtained for monthly and seasonal scales may not necessarily be valid for high temporal resolutions, such as 


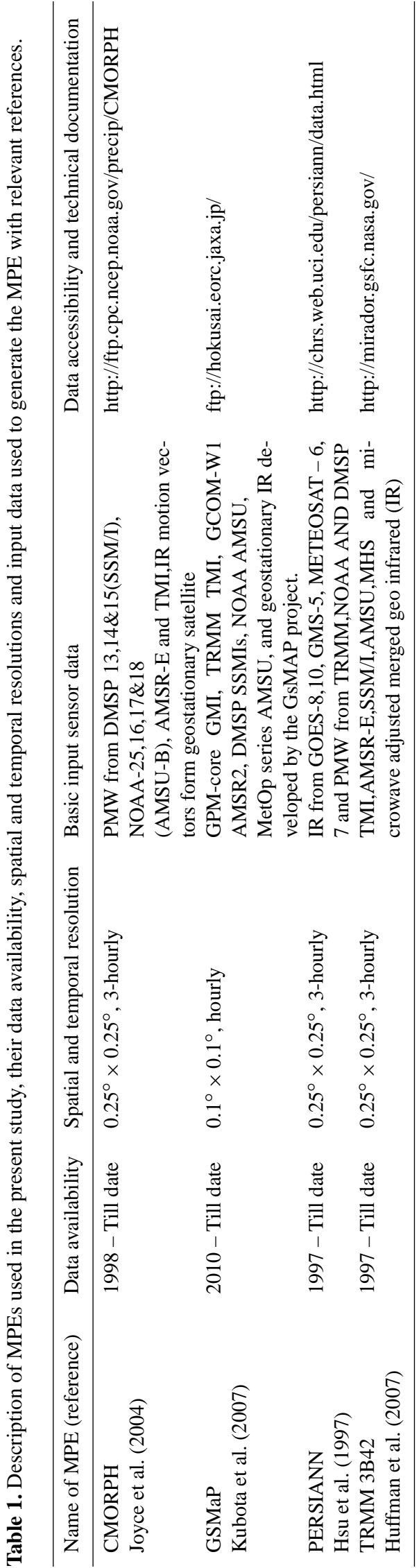

sub-daily scales, and also the performances of MPEs vary in different climatic regions. It is, therefore, highly essential to perform validation independently at finer temporal scales over different climatic regions. As mentioned above, the evaluation of MPEs for monthly and seasonal monsoon precipitation was done to some extent over India (Rahman et al., 2009; Uma et al., 2013; Prakash et al., 2014; Sunilkumar et al., 2015). However, a detailed study on the validation of MPEs at shorter timescales (sub-daily and daily) does not exist due to the lack of suitable measurements. Also, there is no detailed documentation on the small-scale variability of precipitation, discussing the diurnal cycle of precipitation and correlation distance (its dependence on seasons and temporal aggregation of data). The objectives of this paper, therefore, are to quantify and understand the small-scale variability (spatial and temporal) of precipitation over a complex hilly terrain and also to validate high-resolution MPEs using a dense network of rain gauges established around Gadanki $\left(13.45^{\circ} \mathrm{N}, 79.18^{\circ} \mathrm{E}\right)$. This network has been established as part of the Megha-Tropiques (an Indo-French joint satellite mission) validation program (Raju, 2013; Roca et al., 2015). This being the first paper on this network, its establishment and maintenance (stringent calibration procedures adopted) are also discussed briefly. Although the southwest monsoon (SWM: June through September) is the main monsoon season for India as a whole, the southern part of India (including the study region) receives a significant amount of rainfall in the northeast monsoon (NEM: October through December; Rao et al., 2009). The final objective of this paper is, therefore, to understand the seasonal differences in small-scale variability of in situ measured rainfall and performance of MPEs.

The remainder of this paper is organized as follows: a description of the study region including topographical features, seasonal differences and prevailing weather conditions is given in Sect. 2. The establishment and maintenance of the rain gauge network is described in Sect. 3. The morphological characteristics of rain during both monsoon seasons, including the intensity, duration and small-scale variability, are discussed in Sect. 4. The validation of MPEs at sub-daily and daily scales is performed in Sect. 5 using a variety of statistical indices. All the results are summarized in Sect. 6 .

\section{Description of the study region}

The rainfall in India exhibits large and complex spatiotemporal variability governed by a variety of processes, ranging from small-scale convection, orographic lifting and landsea circulations to a gigantic monsoon system. As mentioned above, the SWM season is the primary rainy season when considered for India as a whole, but the southern parts of India receive considerable rainfall during the NEM (Fig. 1a and b). The wind pattern (on the $850 \mathrm{hPa}$ level shown in Fig. 1a and b) also changes dramatically from southwesterlies during 

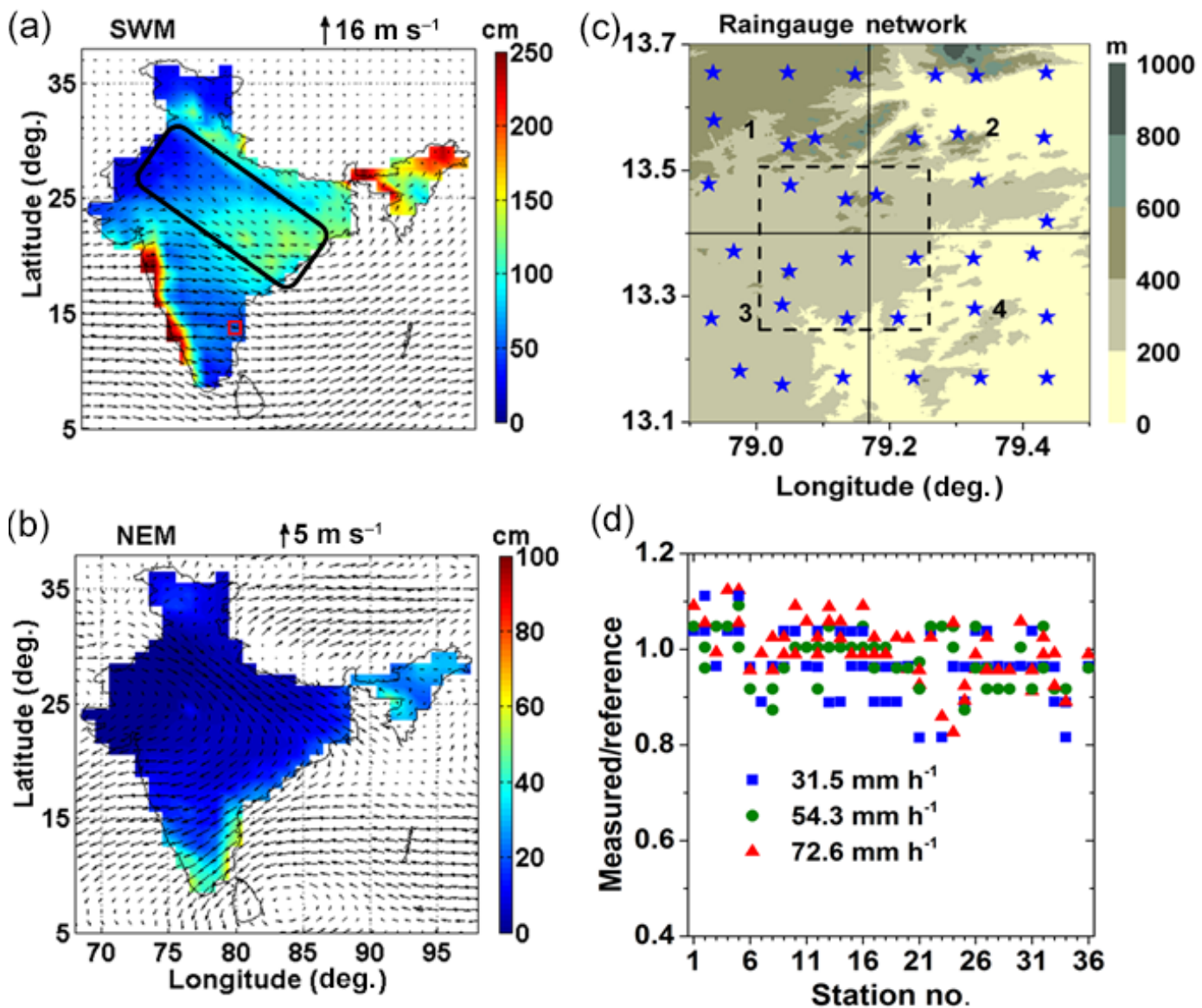

Figure 1. Spatial distribution of mean seasonal rainfall (shading) and wind pattern (arrows) on the $850 \mathrm{hPa}$ level during the (a) SWM and (b) NEM. Note that the scales are different for the SWM and NEM. The black solid contour line covering the north and central India indicates the monsoon trough. The red colored square box in (a) indicates the region of rain gauges. (c) Location of rain gauges in the network (indicated with stars). The shading represents the topography $(\mathrm{m})$. The region is divided into four quadrants and each quadrant is numbered as 1,2,3 and 4. The data in the dashed box are used for the evaluation of MPEs. (d) The ratio of measured and reference (calibrator - Young 52 260) values at three rain rates are shown for each rain gauge location, illustrating the data quality by each gauge.

the SWM to northeasterlies during the NEM over peninsular India. The daily gridded $1^{\circ} \times 1^{\circ}$ rainfall data generated by the India Meteorological Department (Rajeevan et al., 2006) and the European Centre for Medium-Range Weather Forecast (ECMWF) - Interim (ERA; Dee et al., 2011) have been used to generate the above figures. Though the conditions in the Bay of Bengal, like high sea-surface temperature and cyclonic circulations, favor the formation of low-pressure systems, they do not intensify to the stage of cyclone due to the presence of large vertical wind shear during the SWM. These low-pressure systems and depressions move onto the land along the monsoon trough (a quasi-permanent trough that extends from the head Bay of Bengal to northwestern India, covering northern and central India) and produce copious rainfall in this region. By contrast, the low-pressure systems formed in the southern Bay of Bengal often intensify to cyclonic stage during the NEM. These systems move northwestward and produce rainfall along the eastern coast and southern parts of India.

The study region is centered around Gadanki, and spreads in an area of $50 \mathrm{~km} \times 50 \mathrm{~km}$ in Southeast India (shown with a box in Fig. 1a). The National Atmospheric Research Laboratory (NARL) located at Gadanki is responsible for the establishment and maintenance of the gauge network. The topography in the study region is complex, with hillocks distributed randomly on a generally east-west sloped surface (Fig. 1c). There is a steep gradient in the north-south direction also due to the Nallamala Hills (the highest peak is about $1000 \mathrm{~m}$ above sea level) in the north of the study region. The coast is nearly $100 \mathrm{~km}$ away from the center of the study region.

As seen in Fig. 1a and b, the rainfall in this region occurs primarily during two monsoon seasons (SWM and NEM), besides intense thunderstorms in May. While $55 \%$ of the annual rainfall occurs during the SWM, the NEM com- 
prises $35 \%$ of the annual rainfall (Rao et al., 2009). The remaining $10 \%$ occurs during the premonsoon season (March through May). The rain is predominantly convective during the SWM, whereas the stratiform rain fraction is significant and comparable to that of the convective rain fraction during the NEM (Saikranthi et al., 2014). The rain during the SWM occurs primarily due to evening thunderstorms or propagating mesoscale convective systems (Mohan, 2011). This region is far from the monsoon trough and is generally not under the influence of monsoon depressions and low-pressure systems that produce copious rainfall in central and northern India (Houze Jr. et al., 2007; Saikranthi et al., 2014). However, the cyclones with varying intensities play a decisive role in altering the spatial distribution of rainfall during the NEM. During the study period (October 2011 to September 2014), three cyclones and a few depressions formed in the Bay of Bengal and produced copious rainfall in the study region.

\section{A dense rain gauge network around Gadanki}

Dense rain gauge networks are an integral part of validation programs. As part of one such satellite validation program Megha-Tropiques (Raju, 2013; Roca et al., 2015) - NARL established a dense network of rain gauges in 2011, covering an area of $50 \times 50 \mathrm{~km}^{2}$ centered around Gadanki. The network consisting of 36 rain gauges spreads from 78.9 to $79.4^{\circ} \mathrm{E}$ and from $13.1^{\circ} \mathrm{N}$ to $13.6^{\circ} \mathrm{E}$ (Fig. 1c). Rain gauges employed in the present network are of a tipping bucket type with a $20.32 \mathrm{~cm}$ diameter orifice, manufactured by Sunrise Technology (model no. ST-ARS-2011). Each tip corresponds to $0.2 \mathrm{~mm}$ (or $6.4 \mathrm{~mL}$ ) rainfall. The gauges are solar-powered and store high-resolution data at $1 \mathrm{~min}$ resolution at the site on a memory card, which has the capacity to store 5 years of rainfall data. Additionally, the $1 \mathrm{~min}$ data are transferred in near real time about every $30 \mathrm{~min}$ to a server located at NARL using general packet radio service (GPRS) technology. The acquisition of near real-time data is very useful not only for research but also for monitoring the performance of each gauge. It is possible to reset the gauge, if required, from the central hub (NARL). Several factors were considered while choosing the location for rain gauge installation, like its suitability for rain measurement (no obstacle should be there in a cone of $45^{\circ}$ ), safety of the instrument, accessibility to the location and coverage of the mobile network (required for data transfer). As a result, the intergauge spacing is not uniform, but rather varied from 6 to $12 \mathrm{~km}$, although the majority of them are separated by $\sim 10 \mathrm{~km}$ (Fig. 1c). Although the $45^{\circ}$ cone for complete azimuth from the rain gauge is ensured, locations with more clearance in the direction of the wind (predominantly east-west in the study region), wherever possible, have been preferred for the gauge installation.

The reliability of the assessment of MPEs depends primarily on the availability of accurate in situ ground truth provided by the rain gauge network. Though in situ gauge measurements provide better rainfall estimates, they are not error-free. For instance, the systematic errors often noted in tipping bucket rain gauge measurements are attributed to the winds and its induced turbulence, wetting of inner walls of the gauge, loss of rain water during the tipping and evaporation of the rain water in the gauge (WMO, 2008). The estimated wind-induced error through numerical simulations is found to be in the range of $2-10 \%$ for rainfall and increases with decreasing rain rate and increasing wind speed (Nešpor and Sevruk, 1999). The measured surface winds (at $2 \mathrm{~m}$ ) in the study area are in general weak and rarely exceed $4 \mathrm{~m} \mathrm{~s}^{-1}$ $\left(\sim 2 \%\right.$ of the total data $\left.>4 \mathrm{~m} \mathrm{~s}^{-1}\right)$. Therefore, the error due to the wind could be within $5 \%$ in our measurements (Nešpor and Sevruk 1999). The error due to the non-measurement of rain during tipping can be minimized but not eliminated (WMO, 2008). This error is considerable during intense rainfall events. To quantify this error, a rain calibrator with three high flow rates has been used (discussed in detail later).

The gauge maintenance can be challenging, especially in remote locations and in extreme weather conditions, for long durations. The rain gauges are carefully calibrated before deploying them in the field. Strict maintenance schedules are adhered to, which include two regular visits by a qualified technician to all the gauges just before the onset of the two principal monsoon seasons, the SWM and NEM (first visit in May and the second in September), and also to malfunctioning gauges, whenever required, to maintain high-quality data essential for validating high-resolution MPEs. Three types of checks are performed during each visit, besides monitoring the performance of sub-systems, time shifts and temporal offsets between gauges (if any, between the clocks of a gauge and a standard laptop) and battery output. (1) To check how well a rain gauge measures the rain amount, a known quantity of water sufficient for five tips $(5 \times 6.4 \mathrm{~mL})$ is poured slowly into the rain gauge and compared with the number of tips recorded by the gauge. (2) To know whether or not each bucket takes the same quantity of rain for tipping, $6.4 \mathrm{~mL}$ of water is poured slowly into each bucket. The problem, if any is found, is rectified by adjusting the leveling screw. This exercise is repeated till both buckets take the same quantity of water for tipping. Nevertheless, such incidents are rare and these kind of adjustments were required eight times during 3 years. (3) To test how well the gauges estimate different intensities of precipitation, a reference calibrator (Young 52260 ) with three flow rates is employed. The calibrator generates flow rates of 1000,1500 and $2000 \mathrm{~mL} \mathrm{~h}^{-1}$, which corresponds to rain rates of $31.5,54.3$ and $72.6 \mathrm{~mm} \mathrm{~h}^{-1}$, respectively, corresponding to a rain gauge with an orifice diameter of $20.32 \mathrm{~cm}$ (or $8 \mathrm{in}$.). The calibrator is filled with water (up to the mark recommended by the manufacturer) and the water is released into the gauge along the walls of the orifice. By changing the nozzle, the gauge is allowed to record each flow rate for $5 \mathrm{~min}$. The ratios of accumulated rainfall and the estimated rain rate (from the calibrator) for each flow rate are 
estimated. The ratios are estimated at each rain gauge station for all three flow rates and are shown in Fig. 1d. On average, $90 \%$ of the gauges show a ratio in the range of $0.9-1.1$, with a mean value nearly equal to 1 , indicating that the gauges are fairly accurate.

\section{Small-scale variability of rain}

The small-scale variability of rain distribution in a hilly terrain, such as the present study region, depends on several factors from the horizontal scale of mountains, direction of wind to complex interactions between flow dynamics and cloud microphysics (Zängl, 2007, and references therein) besides the differences in large-scale forcing. This section focuses on the small-scale variability of rain, both in space and time, using 3 years of gauge measurements.

\subsection{Morphological features of rain over the study region}

To understand the morphological features of rain and also to test how different its pattern is from that of climatology, the spatial distribution of mean seasonal rainfall for the SWM and NEM is examined (Fig. 2). The mean is taken over 3 years of seasonal rainfall. The rainfall distribution is somewhat uniform during the SWM, while it shows a large gradient towards the northeast during the NEM. The magnitude of seasonal rain is larger in the SWM $(\sim 400 \mathrm{~mm})$ compared to the NEM $(200-350 \mathrm{~mm})$. The rainfall during the SWM accounts for $55 \%$ of the annual rainfall, while the NEM contributes $30-35 \%$, consistent with the seasonal rain fractions reported by Rao et al. (2009). In general, the region along the eastern coast, particularly close to the southern tip of India, receives more rainfall during the NEM, the main monsoon season for that region. However, the rainfall gradually decreases towards the west from the eastern coast. The present study clearly shows this gradient in seasonal rainfall, with rainfall varying by $>100 \mathrm{~mm}$ in just $50 \mathrm{~km}$. This east-west gradient is not the same at all latitudes, but is larger towards the north. The highest mountains in the study region lie in that part and are responsible for lifting the moist air from the Bay of Bengal, reaching that region as part of NEM circulation.

The study region receives rainfall due to a variety of processes, starting from small-scale evening thunderstorms to synoptic-scale cyclones. The rainfall occurred during both monsoon seasons is considered for the present study, irrespective of its generating mechanism (thunderstorm, cyclone, etc.). Nevertheless, to know which kind of rain systems (small-scale/short-lived or large-scale/long-lived) contribute more to total rain amount, the data are segregated into two groups as small-scale/short-lived and large-scale/longlived and rain fractions associated with those systems are estimated at each rain gauge location during both monsoon
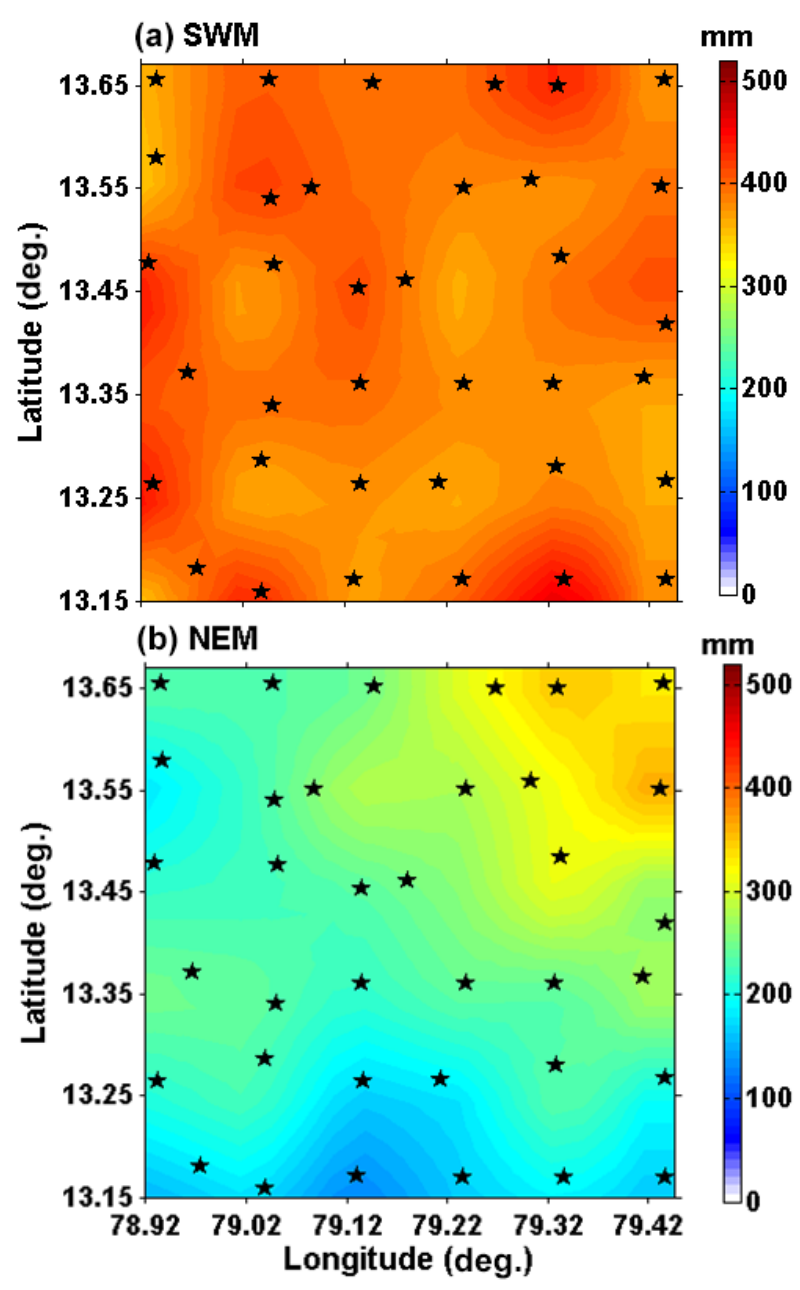

Figure 2. Spatial distribution of average seasonal rainfall for the (a) SWM and the (b) NEM. Also overlaid is the location of rain gauges.

seasons. The system is treated as large-scale/long-lived, if rain occurs over more than $75 \%$ of the gauge locations for at least 2 days. Remaining rainfall is treated as associated with small-scale/short-lived systems. The number of largescale/long-lived systems and their duration varied from year to year. On average, the number of large-scale/long-lived systems during the SWM and NEM is found to be equal, but their average durations differ (6.9 days for the SWM and 4.4 days for the NEM). The rain fraction due to largescale/long-lived systems varies considerably (10-15\%) from year to year during both the seasons. However, the probability distributions of rain fraction by large-scale/long-lived systems (not shown here), clearly depicts the seasonal variation. The large-scale/long-lived systems contribute more to total rain amount during the NEM with $3 / 4$ of locations receive $>60 \%$ of seasonal rain due to these systems. However, same amount of rain fraction $(>60 \%)$ by large-scale/longlived systems is observed only at $1 / 2$ of the locations during 


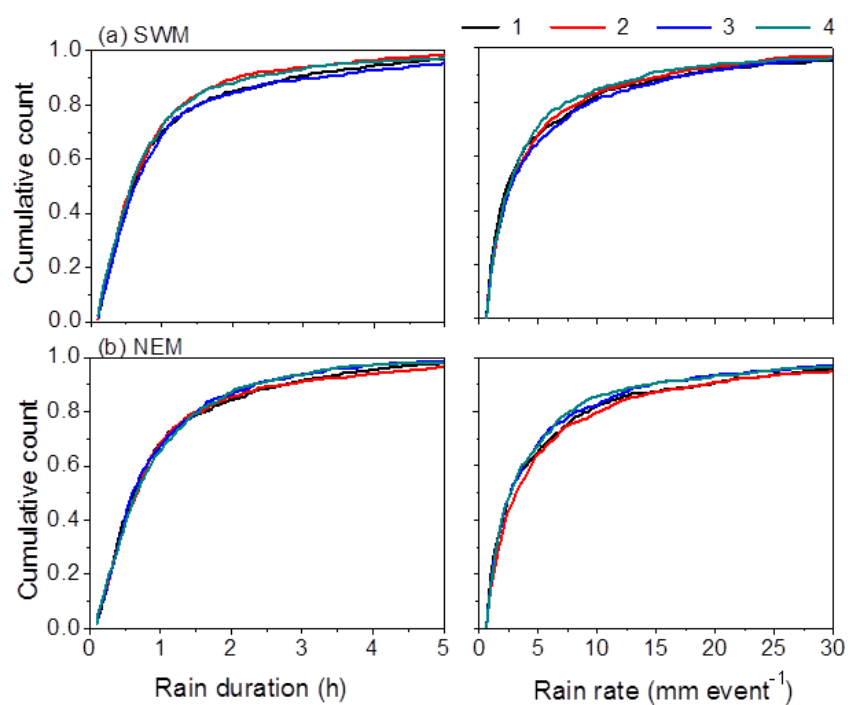

Figure 3. Cumulative distributions for event duration and rain accumulation within the event in four quadrants (color-coded) of the study region during (a) the SWM and (b) the NEM, depicting the regional variability in rain events.

the SWM. Though, the number of rainy days associated with large-scale/long-lived systems (due to longer average duration) is larger during the SWM, but their contribution at many of the locations within the study region is not much. In other words, the small-scale/short-lived systems are also important during the SWM as they produce considerable fraction of total rain amount.

\subsection{Regional variability in rain rate and rain duration}

Based on the topography and spatial distribution of rainfall, the study region is roughly divided into four quadrants (Fig. 1c). The division appears arbitrary but intuitive. The rain gauge locations towards the west, i.e., regions 1 and 3 , are on elevated land and receive a nearly equal amount of rainfall in both seasons. The locations in regions 2 and 4 are on lowland, but the amount of rainfall that they receive varies considerably during the NEM.

To understand the spatial variability within the study region and between the two monsoon seasons, an event-based analysis is performed. As discussed above, the total study region is divided into four quadrants in such a way that nine gauges exist in each quadrant. Rain events at each gauge location within each quadrant are pooled separately for all four quadrants. In the present study, the rain event is defined (for each rain gauge location) as an event with a rain duration $>5 \mathrm{~min}$ and accumulated rain exceeding $0.5 \mathrm{~mm}$. Furthermore, the temporal gap between any two rain events should not be less than $25 \mathrm{~min}$. If rain occurs again within $25 \mathrm{~min}$ after the first shower, then it is considered to be part of the first shower. The $25 \mathrm{~min}$ threshold is chosen as the gauge takes nearly $25 \mathrm{~min}$ for one tip in the presence of driz- zle, at $0.5 \mathrm{~mm} \mathrm{~h}^{-1}$ (assuming rain is continuous and evaporation is negligible). Rain duration and accumulations are estimated from these rain events and their cumulative distributions are shown in Fig. 3. Rain event statistics (of event duration and accumulated rainfall) for each quadrant, like mean, maximum and interquartile range (IQR: 75-25\%) and 90th percentile, are presented in Table 2. The 90th percentile is considered for representing the extreme rainfall events. The above statistics are presented for both the SWM and NEM to delineate the seasonal differences, if any exist.

During both monsoons, the number of rain events is sufficiently large (>500) in each quadrant for obtaining robust statistics. The number of events is largest in the second quadrant in both monsoons, a quadrant in which most of the gauges are located near the foot hills of relatively high mountains, suggesting possible influence of mountain flows in enhancing cloud activity in this quadrant. In general, more rain events are observed during the SWM than in NEM in all quadrants. The SWM is a summer monsoon and most of the rainfall in this season is associated with evening convection due to intense heating, mesoscale flows (convection due to mountain and sea-breeze circulations) (Simpson et al., 2007) and propagating systems (Mohan, 2011) (discussed in detail later). Many of them are short-lived as can be evidenced from their cumulative distributions (Fig. 3). For example, $50 \%$ of the events during the SWM have durations $<35$ min compared to $\geq 40 \mathrm{~min}$ in NEM in all quadrants.

A sensitivity analysis has been performed (not shown here) to understand the impact of thresholds used in the present study ( $25 \mathrm{~min}$ for separating rain events and a rain rate $<0.5 \mathrm{mmevent}^{-1}$ for omitting the events from the analysis) on distributions for event duration and rain rate $\left(\mathrm{mm} \mathrm{event}^{-1}\right)$. Three years (October 2011 to September 2014) of impact-type disdrometer data collected at NARL, Gadanki have been used as it provides $1 \mathrm{~min}$ rain rates (Rao et al., 2001). The distributions for event duration and rain rate have been generated by employing three different temporal intervals for separating rain events, 25, 60 and $120 \mathrm{~min}$. As expected, the distributions for rain duration shifted to longer durations with the increase in time for shower separation. Nevertheless, the rain rate distribution remained nearly the same. The impact of omission of data with rain rates $<0.5 \mathrm{~mm} \mathrm{event}^{-1}$ is also found to be negligible.

During the SWM, the statistics of rain events in two western quadrants are different from those of eastern quadrants. It is clear from Fig. 3a and Table 2 that both the duration of the event and rain accumulation within the event are larger in quadrants 1 and 3 than in 2 and 4 . The difference is quite pronounced in the case of extreme rainfall events (i.e., 90th percentile). Over the study region, the long-lasting events that produce copious rainfall generally occur during the late night-midnight period during active monsoon spells. Mohan (2011), using a Hovmöller diagram of 3-hourly TMPA rainfall, has shown that these long-lasting rain bands are propagating systems from the west coast. These systems start 
Table 2. Statistics of rain storms in each quadrant during the SWM and NEM. The statistics include the number of storms and mean, IQR, 90th percentile and maximum values for storm duration and accumulated rain within the storm.

\begin{tabular}{lrrrrrrrrrr}
\hline & \multicolumn{9}{c}{ Rain duration (min) } & \multicolumn{7}{c}{ Accumulated rainfall (mm) } \\
\hline Region/season & $\begin{array}{r}\text { No. of } \\
\text { events }\end{array}$ & Mean & IQR & 90th & Max & Mean & IQR & $90 \%$ & Max \\
\cline { 2 - 10 } SWM & & & & & & & & & \\
\hline 1 & 674 & 64.5 & 55 & 169 & 456 & 6.58 & 6.2 & 17.4 & 70.8 \\
2 & 792 & 55.3 & 47 & 123 & 423 & 6.04 & 5.6 & 16 & 81 \\
3 & 774 & 70.1 & 52 & 193 & 592 & 6.65 & 6.5 & 17.8 & 76 \\
4 & 670 & 58 & 47 & 133 & 462 & 5.83 & 4.6 & 14.2 & 86.4 \\
\hline NEM & & & & & & & & & \\
\hline 1 & 549 & 65.6 & 55 & 167 & 656 & 6.55 & 6.2 & 19.6 & 79.8 \\
2 & 746 & 67.1 & 55 & 167 & 478 & 7.26 & 6.2 & 18.8 & 126 \\
3 & 565 & 60.2 & 56 & 140 & 521 & 5.76 & 5.2 & 14.6 & 65.4 \\
4 & 514 & 68 & 58 & 138 & 1425 & 6.02 & 5.1 & 14.4 & 99.6 \\
\hline
\end{tabular}

propagating from the west coast in the evening and reach the study region, which is nearly $400 \mathrm{~km}$ from the west coast (see Fig. 1a), around midnight. Inspection of background meteorological parameters like low-level wind shear and convective available potential energy (CAPE) reveals that the propagation could be associated with wind shear-cold pool interaction on the down shear regime (Weisman and Rotunno, 2004). The intensity of propagating systems gradually diminishes as they move from the west to the east. At times, these propagating systems produce rainfall over the gauge locations in the western quadrants, but not in eastern quadrants, because the rain bands dissipate before reaching the eastern quadrants. This is depicted in pictorial form in Fig. $4 \mathrm{a}$ and $\mathrm{b}$ for the SWM and NEM, respectively, showing the event duration and rain accumulation as a function of local hour in all quadrants. The number, duration and rain accumulation of events during 19:00-04:00 IST (Indian Standard Time) in the western quadrants exceeds those in the eastern quadrants. Also, events with a longer duration and greater rain accumulation are almost absent during the morning-noon period (08:00-12:00 IST) in the western quadrants, while a few such events exist in the eastern quadrants. It is strikingly apparent from Fig. 4a that there is a clear diurnal pattern in event duration in all four quadrants, though the pattern appears to be smeared in the eastern quadrants. The eastern quadrants, being relatively closer to the coast, may sometimes get rain due to sea-breeze intrusions (Simpson et al., 2007). This coupled with the inability of some propagating systems to reach these quadrants appear to be the reasons for a different diurnal pattern.

Significant regional variability is also observed in rain duration and accumulation during the NEM, wherein the northern quadrants (numbered 1 and 2) experience long-lasting events with more rainfall than their counterparts in the southern quadrants (numbered 3 and 4) (Figs. 3b and 4b). Almost all the long-lasting events in the northern quadrants (1 and 2) produced a significant amount of rainfall $(>20 \mathrm{~mm})$, while it is not the case in the southern quadrants. The north-south regional differences are distinctly apparent in extreme rainfall cases also (90th percentile) (Table 2). Events with the longest duration and highest rainfall, on the other hand, are seen in the eastern quadrants. For example, the fourth quadrant has six events with a duration longer than $10 \mathrm{~h}$, with one event producing rainfall continuously for nearly 1 day (1425 min). This event is associated with a cyclone, Neelam, that passed close ( $\sim 50 \mathrm{~km}$ south of Gadanki) to the observational site on 31 November 2012. In fact, this cyclone has produced steady rainfall over several rain gauge locations leading to long-lasting events ( 16 events with durations longer than $6 \mathrm{~h}$ are observed during the passage of Neelam). This number increased to 53, when events of $3 \mathrm{~h}$ or longer are considered. The observed IQR for rain duration also shows a different pattern during the NEM, where the values in all quadrants are not significantly different from each other. In contrast to the clear diurnal pattern in rain events and duration during the SWM, the NEM does not show any clear signature of diurnal pattern.

\subsection{Diurnal variability}

Figure 4 clearly demonstrated the diurnal pattern in the number of events and duration in both the monsoon seasons. This section further discusses the spatial and seasonal variability in the diurnal cycle of rainfall. The diurnal variation is the fundamental mode of variability in the precipitation time series and the time of occurrence of maximum rainfall depends on several factors, like the underlying surface (land or ocean), mesoscale circulations, topography, etc. (Nesbitt and Zipser, 2003; Janowiak et al., 2005; Yang and Smith, 2006; Kikuchi and Wang, 2008). Since the study region is located 
(a) SWM

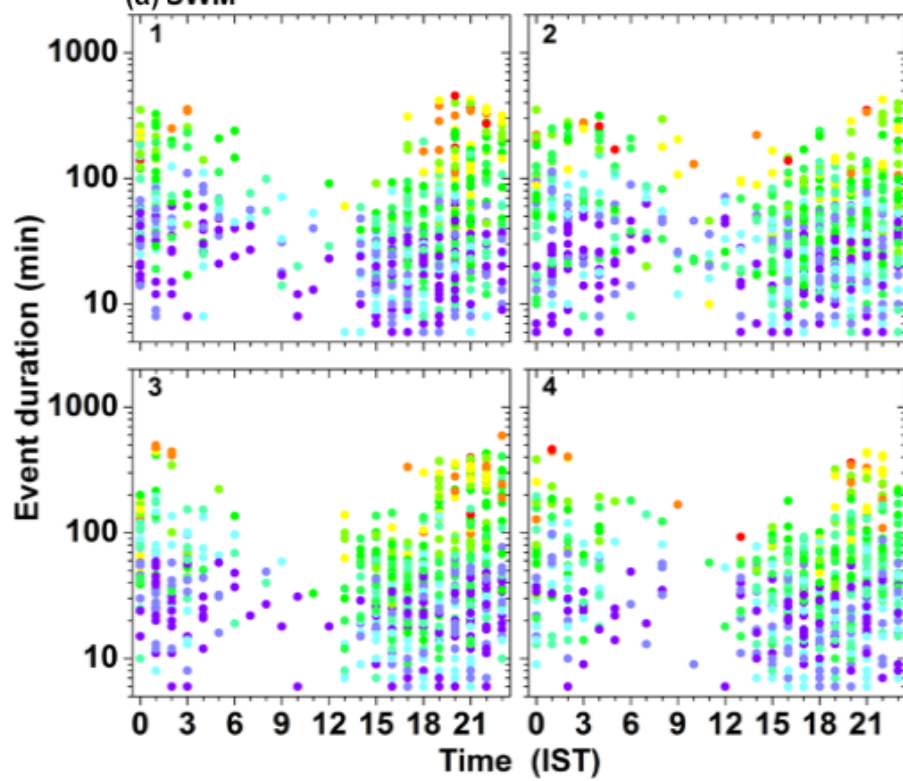

(b) NEM

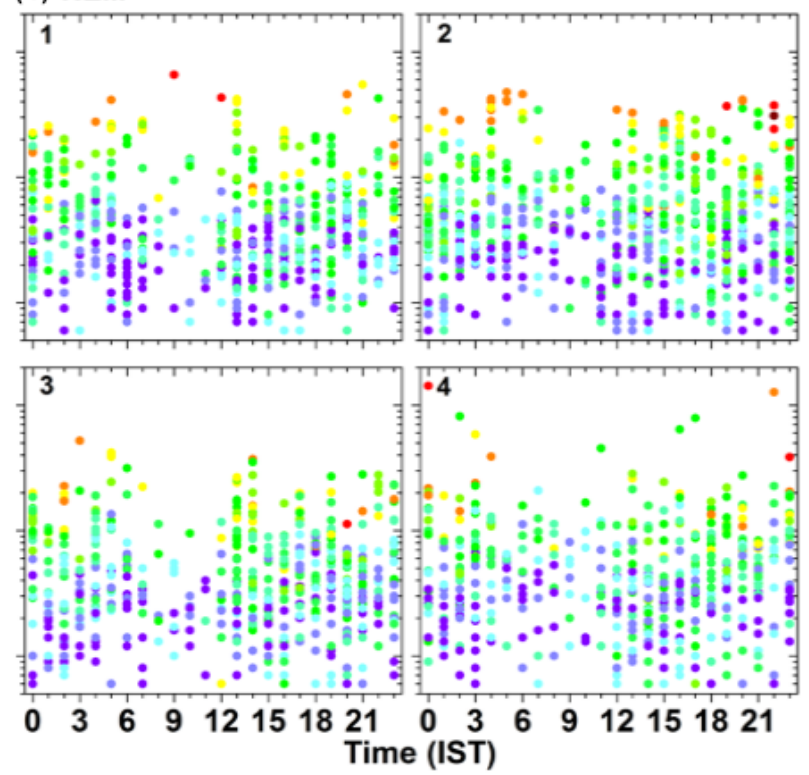

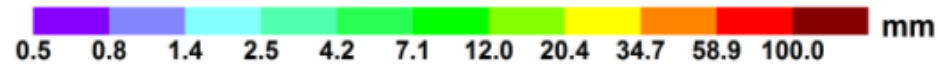

Figure 4. Diurnal variation of event duration and rain accumulation in four quadrants of the study region during (a) the SWM and (b) the NEM. Accumulated rain (in $\mathrm{mm}$ ) is shown in the color bar.

in a complex hilly terrain and is about $75-125 \mathrm{~km}$ from the coast, several mesoscale circulations triggered by topography and land-sea contrast, besides the propagating systems, could alter the rainfall pattern. To better understand these processes during the SWM and NEM, the diurnal variation of rainfall at each location has been studied during the two monsoon seasons.

The mean hourly rainfall (hourly accumulated rainfall from all the days in a season/number of days) time series at each gauge location is subjected to harmonic analysis. The amplitude and phase of the diurnal cycle, thus obtained, at each location is depicted in Fig. 5 for both SWM and NEM. The arrow magnitude and direction represent the amplitude and phase (time of maximum rainfall in the form of a $24 \mathrm{~h}$. clock) of the diurnal cycle, respectively. For instance, the arrow pointing up $\left(0^{\circ}\right)$, right $\left(90^{\circ}\right)$, down $\left(180^{\circ}\right)$ and left $\left(270^{\circ}\right)$ denote, respectively, the rainfall maxima at 00:00, 06:00, 12:00 and 18:00 IST. The statistical significance of the amplitude is evaluated by using the F-statistic (Anderson, 1971). Statistically insignificant amplitudes are shown with blue arrows. The topography is also shown in the figure (shading) for easy visualization of mountain effects, if any, on the diurnal cycle.

Clearly, the rainfall shows distinctly different diurnal cycles during SWM and NEM. Except for one location, the diurnal cycle is significant with large amplitudes at all locations during the SWM. Though the diurnal cycle is insignificant at one location (station numbered 10), the seasonal rainfall at this location does not show any anomalous behavior (the seasonal rainfall at this location is nearly equal to that of its surrounding locations). On the other hand, the diurnal cycle is insignificant at several locations (15) during the NEM. Even those locations at which the diurnal variation is significant, the amplitudes are smaller than those observed during SWM. For instance, during the SWM, 17 locations show diurnal amplitudes larger than the largest diurnal amplitude in NEM. On average, the diurnal amplitudes are larger by a factor of $\sim 2$ in SWM than in NEM.

The diurnal cycle also exhibits spatial variability during both monsoon seasons. The diurnal cycle is stronger in western quadrants of the study region during the SWM, as evidenced by the large diurnal amplitudes. Though several rain events occur during the afternoon - evening period ( $\sim 40 \%$ of total events occur during 14:00-19:00 IST), most of them are short-lived and contribute only $30 \%$ to the seasonal rainfall. On the other hand, $50 \%$ of total events occur during 20:00-00:00 IST, but they occupy $\sim 60 \%$ of seasonal rain amount (Fig. 4). Among four quadrants, the rain fraction by events occurring during 20:00-00:00 IST is highest in western quadrants (1 and 3, wherein it exceeds 62-67\%). The diurnal cycle shows a broad peak during 20:00-00:00 IST at all the locations with maxima at 21:00 IST. One would expect an evening peak in the diurnal cycle of rainfall over the land, when the convective instability induced by solar heating increases, resulting cloud formation and precipitation. However, the diurnal cycle in rainfall in the study region peaks 

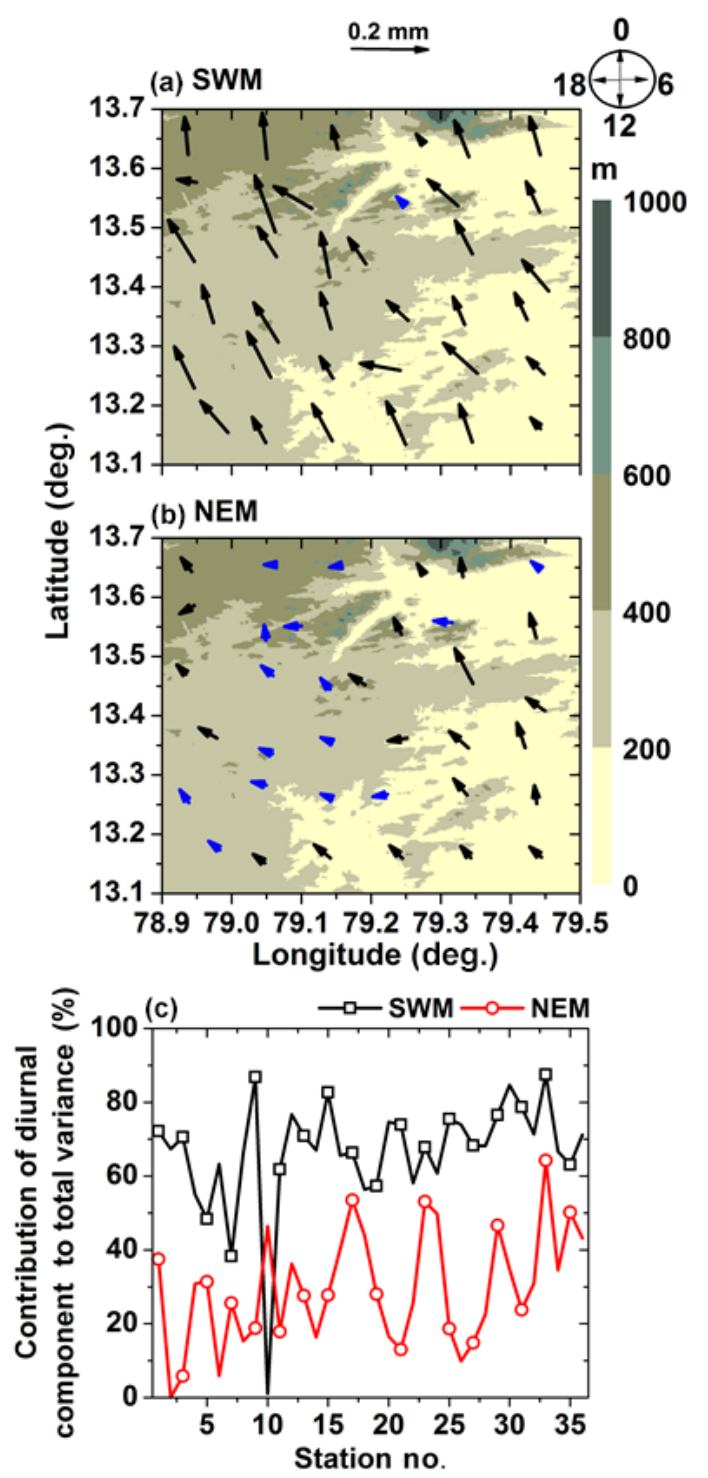

Figure 5. Diurnal variation of rainfall at all rain gauge locations during the (a) SWM and (b) NEM. The vector length and pointing arrows indicate the amplitude and phase (peak rainfall hour), respectively, of the first harmonic. The shading and blue arrows indicate, respectively, topography and insignificant diurnal amplitudes. (c) Percentage contribution of variance by first harmonic to the total variance at each rain gauge location during both monsoons.

much later and this peak is primarily associated with the propagating systems (Mohan, 2011).

During the NEM, except for 6 locations that show an evening peak (16:00-18:00 IST) in the diurnal cycle, all other locations (30) depict a broad peak during 18:00-22:00 IST. In this season, the rainfall is governed by a variety of processes, like depressions/cyclones originating in the adjoining Bay of Bengal, small-scale evening thunderstorms, advection of nocturnal precipitating systems from the Bay of Bengal, mountain-induced rainfall (either by lifting the moist air reaching the study region with the synoptic flow or by generating convergence zones for convection during the night). These processes generate rainfall that either does not show any diurnal cycle (like cyclones) or peaks at different timings (solar heating-induced convection peaks during the evening, rainfall due to advection from the Bay of Bengal in the morning, mountain-induced rainfall during the night), producing a weaker (in some cases insignificant) diurnal cycle of rainfall. The spatial variability in the diurnal cycle is also considerable, with the majority of the locations in the eastern quadrants showing a significant diurnal cycle. By contrast, the diurnal cycle is insignificant at several locations in the western quadrants.

The present study mainly focuses only on the first harmonic ( $24 \mathrm{~h}$ component) of the diurnal variation, as it is regarded as the dominant mode by earlier studies elsewhere. To examine this issue and also to quantify how much variance the $24 \mathrm{~h}$ component explains in the total variance, both total variance and variance due to $24 \mathrm{~h}$ harmonic are estimated. Figure $5 \mathrm{c}$ shows the contribution of $24 \mathrm{~h}$ harmonic to the total variance at each rain gauge location during SWM and NEM seasons. It is clearly evident from Fig. $5 \mathrm{c}$ that the $24 \mathrm{~h} \mathrm{com}$ ponent is the dominant mode in the diurnal variation of rainfall during the SWM. It explains $40-90 \%$ of the total variance of the diurnal cycle at different locations with an average contribution of $\sim 70 \%$. Only one station (No. 10), where the diurnal cycle is insignificant (Fig. 5a), shows less contribution to the diurnal variance. On the other hand, the contribution of $24 \mathrm{~h}$ harmonic to the total variance is mere $\sim 30 \%$ (on average) during the NEM, indicating that other high frequency modes might be important during the NEM. Also, the diurnal component contributes $<20 \%$ to the total variance at several locations ( $1 / 3$ of total number of locations). As discussed above, several processes including the evening convection, early morning rain due to oceanic clouds, wide spread and continuous cyclonic rain weaken the diurnal cycle during the NEM.

\subsection{Spatial correlation}

To understand the similarities and differences in spatial coherence of rainfall between the two monsoon seasons, correlation analysis is performed. Earlier studies have shown the usefulness of such analysis in gauge-satellite comparisons, hydrological and meteorological modeling and setting up gauge networks (Habib et al., 2001; Krajewski et al., 2003; Ciach and Krajewski, 2006; Villarini et al., 2008; Liechti et al., 2012; Luini and Capsoni, 2012; Mandapaka and Qin, 2013; Li et al., 2014; Chen et al., 2015). Spearman correlation coefficients have been computed between each pair of rain gauge locations for different rain accumulation periods. In the present study, four accumulation periods are considered $(1,3,12$ and $24 \mathrm{~h})$ to understand the spatial correlation structure on varying rain accumulation periods (temporal scales). 
(a) SWM

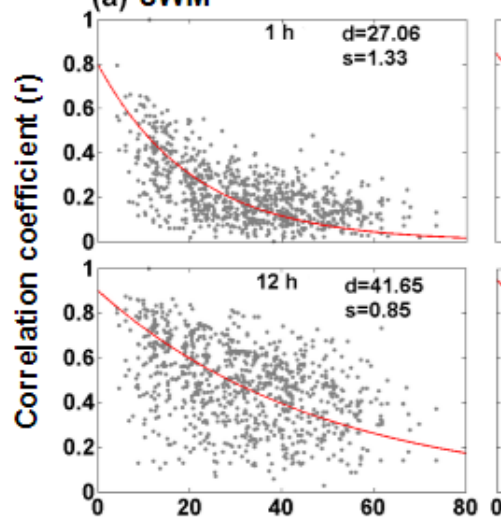

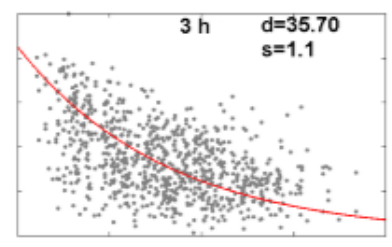

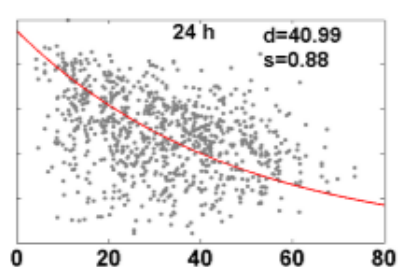

20 (b) NEM

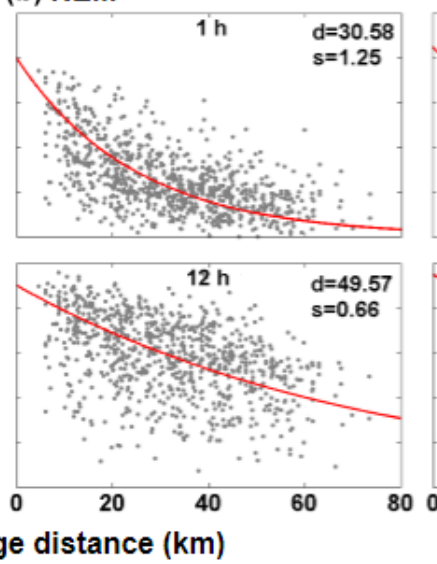

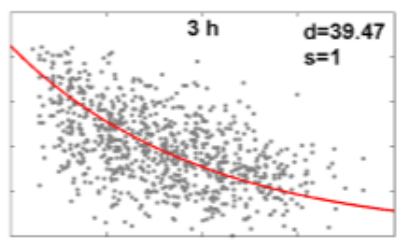

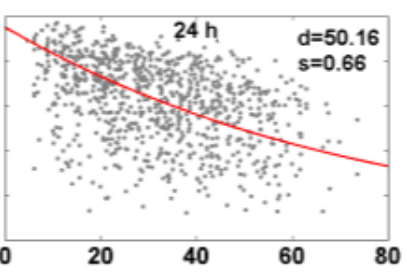

Intergauge distance $(\mathrm{km})$

Figure 6. Correlograms (correlation coefficient vs. intergauge distance) for 1, 3, 12 and $24 \mathrm{~h}$ rain accumulations during the (a) SWM and (b) NEM. The red curve indicates the fitted modified exponential function to the data. The accumulation period, slope of the curve and spatial correlation distance are also shown in each plot.

The spatial correlation of rainfall between different rain gauge locations at different rain accumulation periods (1, 3, 12 and $24 \mathrm{~h}$ ) is plotted as a function of gauge distance in Fig. 6 ( $a$ for the SWM and $b$ for the NEM). The spatial correlation distance is obtained by fitting a modified exponential model on the data samples in correlograms (intergauge correlation coefficient vs. intergauge distance), as given by Ciach and Krajewski (2006),

$\rho(d)=\rho_{0} \exp \left[-\left(d / d_{0}\right)^{s_{0}}\right]$,

where $\rho_{0}$ is the nugget parameter signifying the local decorrelation (caused by random instrumental errors), $d$ is the distance between the pair of gauges (varies from 6 to $73.5 \mathrm{~km}$ in the present study), $d_{0}$ is the correlation distance (or scale parameter) and $s_{0}$ is the shape parameter. The integration time, $d_{0}$ and $s_{0}$ are also depicted in the figure for ease of comparison.

It is clearly evident from Fig. 6 that the correlation decreases with increasing gauge distance and increases with the accumulation time, consistent with earlier studies (Krajewski et al., 2003; Villarini et al., 2008; Luini and Capsoni, 2012; $\mathrm{Li}$ et al., 2014). The steepest decrease in correlation is observed with $1 \mathrm{~h}$ integrated rain, which shows insignificant correlation $(<0.2)$ after $\sim 30 \mathrm{~km}$. Furthermore, the spatial correlation (in terms of correlation distance and slope) varies rapidly with timescales up to $3 \mathrm{~h}$, but remains nearly the same for rain accumulations of 12 and $24 \mathrm{~h}$. The correlograms for all rain accumulations show large scatter around the model curve even at shorter gauge distances. The large scatter indicates that the rainfall in the study region is quite variable both in space and time. Because of this large variability even at shorter distances, the nugget parameter shows values in the range of $0.8-0.95$ (for different accumulations). These features are observed during both monsoon seasons, albeit with differing slopes and correlation distances. The correlation characteristics exhibit some seasonal variation for all rain accumulations, as evidenced by different correlation distance and slope values during the SWM and NEM. The correlation distances (slope) during the NEM are found to be larger than in the SWM, indicating a higher spatial correlation of rainfall during the NEM. The observation of weaker correlation during the SWM than in the NEM is consistent and analogous to earlier reports that show smaller correlation distances during summer than in winter (Baigorria et al., 2007; Dzotsi et al., 2014; Li et al., 2014). Weak correlation in summer is attributed to the large spatial variability of rainfall due to highly localized and short-lived convective systems (Krajewski et al., 2003; Dzotsi et al., 2014; Li et al., 2014). It indeed is true that such systems occur frequently during the SWM over the study region (Figs. 3 and 4).

\section{Validation of high-resolution MPEs}

As mentioned in Sect. 1, several evaluation studies exist in the literature focusing on the assessment of seasonal rainfall over India (Uma et al., 2013; Prakash et al., 2014; Sunilkumar et al., 2015), but none of them dealt with high-resolution (temporal) measurements. This aspect has been studied in detail in this section, in which the focus is primarily on the validation of high-resolution MPEs using a variety of metrics and statistical distributions and also on the diurnal cycle of rainfall. As seen in Table 1, MPEs provide precipitation information with different temporal and spatial resolutions. For proper assessment of MPEs, they need to be uniform and should match with the reference. First, all MPEs are temporally integrated for $3 \mathrm{~h}$ and then remapped onto $0.25^{\circ} \times 0.25^{\circ}$. The study region, therefore, will have four satellite grid points. Among them, one grid point is chosen (for the validation) $\left(13.375^{\circ} \mathrm{N}, 79.125^{\circ} \mathrm{E}\right)$ in such a way 
that the grid point is close to the center of the network and the rainfall and terrain are somewhat homogeneous around that grid (dashed box covering a region of $0.25^{\circ} \times 0.25^{\circ}$ in Fig. 1c). Moreover, the diurnal cycle at all locations (nine in number) within the selected region is somewhat similar. The intergauge spacing within the selected region is in the range of 6-12 km, which is much smaller than $d_{0}$ of 3-hourly rainfall in this area (Fig. 6). It is known from earlier studies that the density of operational gauges is often too small to resolve the rainfall variations at smaller scales (Habib et al., 2009). However, the 6-12 km intergauge distance employed here is almost equal to the highest resolution given by MPEs (i.e., $8 \mathrm{~km}$ by CMORPH), and therefore they can serve as a reference for validating high-resolution MPEs. However, to match the resolution of other MPEs $\left(0.25^{\circ} \times 0.25^{\circ}\right)$, the rainfall data at the selected grid are obtained by interpolating (using inverse distance weighting) the data at all the locations within the selected region. Furthermore, to discard the rain data arising due to the gridding, a rain threshold of $0.5 \mathrm{~mm}$ per $3 \mathrm{~h}$ is used as a lower threshold to discriminate the rain from no rain.

The validation of rain rates generated by MPEs is performed in a statistical way by comparing the cumulative distributions of $3 \mathrm{~h}$ rain rates by MPEs with a rain gauge network (Fig. 7). Note that the frequency bins of cumulative distribution are taken for logarithmic values of $3 \mathrm{~h}$ rain rates. Figure 7 clearly shows that all MPEs severely underestimate

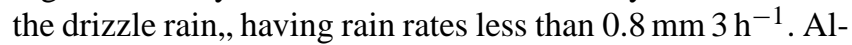
though the underestimation at low rain rates is seen during both monsoon seasons, it is severe in the NEM. Later it will be shown that this underestimation is partly due to MPEs' inability to detect the light rain and partly due to the underes-

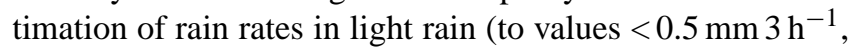
the threshold used to detect the rain). Among different data sets, the underestimation is severe in the case of TMPA, but is less so in PERSIANN. While the distributions for MPEs and the reference show a very good agreement for rain rates $1-8 \mathrm{~mm} 3 \mathrm{~h}^{-1}$, all MPEs overestimate rain rates during

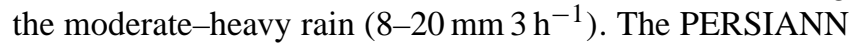

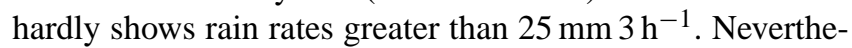
less, the number of samples in higher rain rate bins is quite small and needs to be dealt with carefully.

All MPEs are validated for their detection capabilities and also for quantifying the root mean square error (RMSE) at two temporal resolutions ( 3 and $24 \mathrm{~h}$ ). While $3 \mathrm{~h}$ corresponds to the highest temporal resolution that most of MPEs provide, the $24 \mathrm{~h}$ rain accumulation is the commonly used temporal integration in such evaluation studies (Ebert et al., 2007; Habib et al., 2012; Sunilkumar et al., 2015 and references therein). Table 3 shows validation statistics in terms of detection metrics (in \%) (Probability of detection (POD- both reference and MPEs detect the rain correctly), false alarm ratio (FAR- MPEs detect the rain wrongly), misses (missing rainMPEs fail to detect the rain)), and accuracy metrics (correlation coefficient and RMSE; Ebert et al., 2007; Sunilkumar et
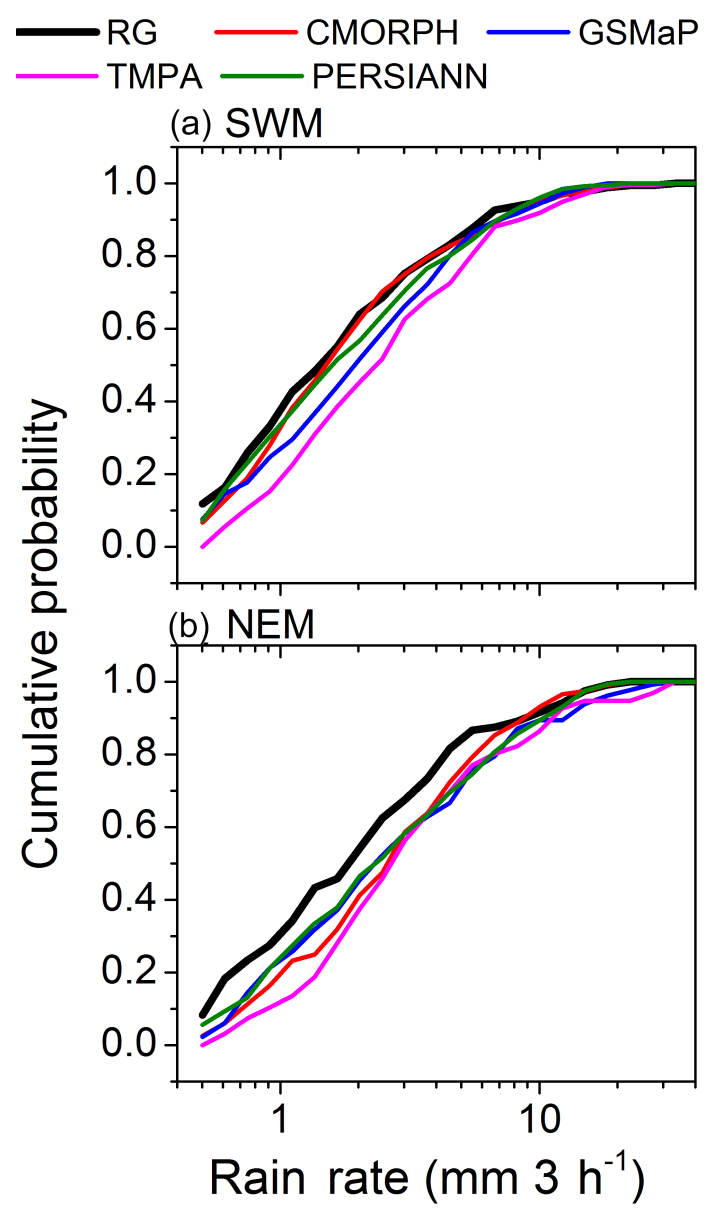

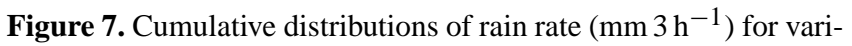
ous MPEs (color-coded) and the rain gauge network at $\left(13.375^{\circ} \mathrm{N}\right.$, $79.125^{\circ}$ E) (black curve) during (a) SWM and (b) NEM.

al., 2015 for formulae). The detection metrics clearly show marked differences between the seasons and also between MPEs within the season. All MPEs exhibit good detection skills of rain at 3 and $24 \mathrm{~h}$ temporal resolutions, however, the $24 \mathrm{~h}$ accumulation provides relatively better statistics (higher POD during both seasons). Although the detection skills of all MPEs improve with higher temporal accumulation, the degree of improvement varied from season to season and also between different data sets. It varied by $\sim 20-65 \%$ during the SWM, but the improvement is only marginal for 3 data sets during NEM (<20\%, but only TMPA shows considerable improvement in POD with longer rain accumulation).

The FAR values validated at $3 \mathrm{~h}$ accumulation are quite small and show large seasonal differences. Examination of data reveals that these small values are due to the large number of non-rainy data points in the reference data (it appears in the denominator). Nevertheless, the FAR values increase with temporal accumulation and are nearly comparable with those available in the literature (Sunilkumar et al., 2015). The study region being a semi-arid region with dry atmo- 
Table 3. Comparison of high-resolution MPEs with reference data in terms of detection (POD, MIS and FAR) and accuracy (RMSE and correlation coefficient) metrics. The comparison has been made at two temporal integrations, $3 \mathrm{~h}$ (first value) and $24 \mathrm{~h}$ (second value).

\begin{tabular}{lllll|llll}
\hline & \multicolumn{4}{c}{ SWM } & \multicolumn{3}{c}{ NEM } \\
\cline { 2 - 9 } & CMORPH & GSMaP & TMPA & PERSIANN & CMORPH & GSMaP & TMPA & PERSIANN \\
\hline RMSE & $3.9,7.8$ & $4.4,9.4$ & $5.1,7.7$ & $4.1,9.5$ & $5.5,13.8$ & $6,16.6$ & $6.2,10.2$ & $5.4,12.2$ \\
CORR. & $0.4,0.6$ & $0.1,0.3$ & $0.2,0.6$ & $0.1,0.3$ & $0.3,0.4$ & $0.2,0.5$ & $0.3,0.6$ & $0.1,0.5$ \\
FAR & $8.3,18.8$ & $10.8,24.4$ & $8.2,24.4$ & $16.5,46.1$ & $3.6,1.6$ & $5.2,7.2$ & $2.9,2.4$ & 7,12 \\
MIS & $32,18.8$ & $46.6,18.8$ & $50,17.8$ & $47.7,13.8$ & $42.5,38.3$ & $49.2,38.3$ & $53.3,31.6$ & 45,40 \\
POD & $67.9,81.8$ & $53.3,81.8$ & $50.8,82.1$ & $52.2,86.1$ & $56.6,61.6$ & $50.8,61.6$ & $46.6,68.3$ & 55,60 \\
\hline
\end{tabular}

spheric conditions, evaporation of falling rain is found to be significant with higher fraction of virga rain (predominant during the SWM) (Radhakrishna et al., 2008; Saikranthi et al., 2014). Since MPEs depend mostly on cloud top temperature or ice scattering signature for deriving rainfall over the land, significant evaporation of falling rain and higher fraction of virga rain results larger FAR values (Sunilkumar et al., 2015). For the same reason, the missing rain is expected to be less. Contrary, the missing rain is found to be quite high in both monsoon seasons, particularly with $3 \mathrm{~h}$ rain accumulation data. Although with $24 \mathrm{~h}$ accumulation, the fraction of missing rain reduced considerably during the SWM, but not in the NEM. Interestingly, the observed percentage of missing rain is comparable to that obtained by Sunilkumar et al. (2015) using an independent data set as the reference $\left(1^{\circ} \times 1^{\circ}\right.$ gridded operational rainfall data set). The reasons for higher fraction of missing rain during the NEM even with longer time integration are not immediately obvious. Several possibilities exist for the observed large fraction of missing rain during the NEM, like higher occurrence of weaker

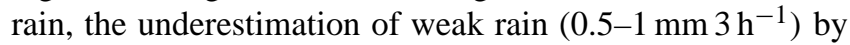
MPEs, and higher occurrence of shallow rain. The data are examined for the existence of such instances in both the seasons. The occurrence percentage of weak rain with rain

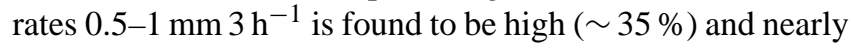
equal in both monsoon seasons, indicating that it may not be the real cause. The second aspect, the underestimation of rain rates by MPEs, could be a decisive factor, particularly in the presence of considerable fraction of weaker rain. If the underestimation of MPEs is such that the $3 \mathrm{~h}$ rain accumulation by MPEs is $<0.5 \mathrm{~mm} \mathrm{~h}^{-1}$, then the algorithm considers it as missing rain. Such cases, indeed, exist in the data and are more frequent during the NEM than in the SWM, but certainly they are not enough to explain the higher missing rain in the NEM. Even if we include them as rain, the missing rain reduces only by $5 \%$. The third aspect is higher occurrence of shallow rain. Earlier studies have shown that the rain top height is indeed low with higher occurrence of shallow rain during the NEM in the study region (Saikranthi et al., 2014). It is also known from earlier studies that most of MPEs suffer in identifying the shallow rain, particularly in the vicinity of mountains (Sunilkumar et al., 2015). Therefore any of the above and or all could be the reasons for the higher occurrence of missing rain during the NEM.

The correlation of rainfall between MPEs and the reference is quite weak and insignificant at $3 \mathrm{~h}$ accumulation, but improved considerably and is significant at $24 \mathrm{~h}$ rain accumulation. The correlation coefficient does not show any clear seasonal difference. On the other hand, the RMSE clearly shows seasonal differences, with smaller values in the SWM than in the NEM. Overestimation of heavy rain coupled with a higher fraction of missing rain and a lower fraction of POD are contributing considerably to a higher RMSE in the NEM. The RMSE increases with the integration time in both monsoon seasons and the daily RMSEs are comparable in magnitude with those available in the literature (Sunilkumar et al., 2015).

Among different MPEs, PERSIANN appears to overdetect the rain as evidenced by larger POD and FAR and smaller missing values. However, because of its inability to detect very heavy rain $\left(>25 \mathrm{~mm} \mathrm{~h}^{-1}\right.$, not shown as a separate figure but can be seen from Fig. 7) and overdetection of rain, PERSIANN produces weak correlation with the reference and large RMSE. This feature is more prominently observed during the SWM. On the other hand, TMPA performs poorly at $3 \mathrm{~h}$ resolution with higher (smaller) values of misses, FAR and RMSE (POD) when compared to other MPEs. However, TMPA improves tremendously and provides much better precipitation estimates at longer temporal integration in both the monsoon seasons. Examination of detection and accuracy metrics in Table 3 reveals that CMORPH-derived precipitation estimates are the best among all MPEs at $3 \mathrm{~h}$ resolution.

Validation of the diurnal cycle of rainfall could be more intriguing, as it is not only poorly represented by numerical models (Betts and Jakob, 2002; Nesbitt and Zipser, 2003), but also distinctly different in different seasons over the study region (Figs. 4-6). Figure 8 shows the comparison of diurnal cycle (with $3 \mathrm{~h}$ unconditional rain rate) obtained by MPEs and reference in both monsoon seasons. Clearly the diurnal cycle is quite strong during the SWM and all MPEs captured the basic shape of the cycle, with nocturnal maximum and morning-noon minimum, quite well. However, all MPEs overestimate the rainfall rate, albeit with different magnitudes, almost throughout the day. The overestimation is se- 


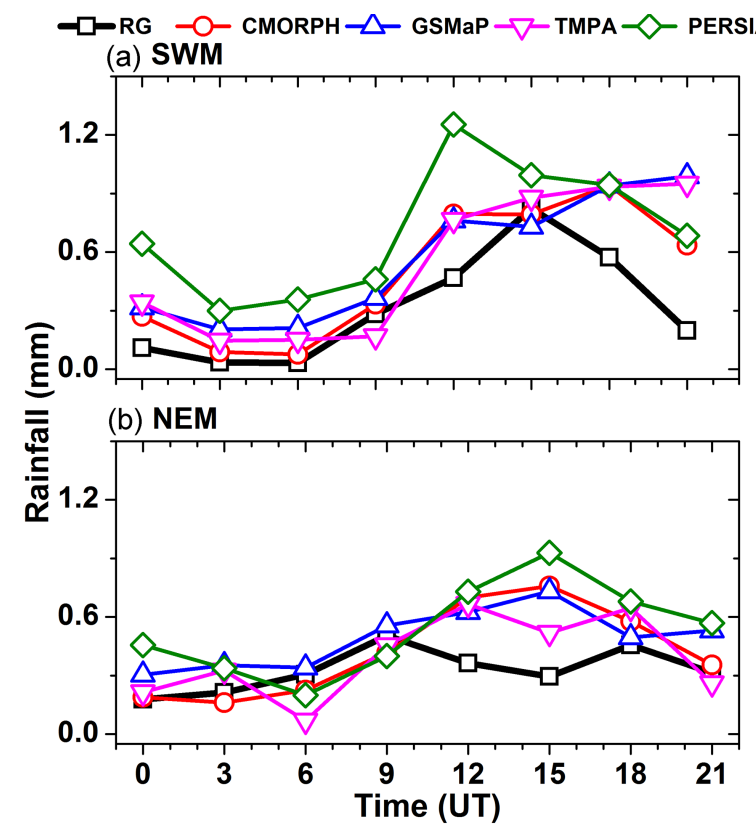

Figure 8. Comparison of diurnal variation of rainfall obtained by various MPEs and the reference data set (rain gauge network) during (a) SWM and (b) NEM. The rain gauge data are integrated to match with the timings of MPE. Note that the time is given in universal time (UT).

vere (as high as a factor of 5) in the case of PERSIANN, while others show relatively small overestimations. While the amplitude of the diurnal cycle by all MPEs is nearly equal, the phase is different for different MPEs. The reference data set peaks at 15:00 UT (universal time $=05: 30$ IST), which is equivalent to 20:30 IST. All MPEs capture the peak with a time lag/lead. While PERSIANN peaks $3 \mathrm{~h}$ prior to the reference-peak time, others peak 3-6 h later. It is known from earlier studies that MPEs that depend heavily on IR data show a lagged diurnal cycle due to the lag between the detection of clouds and the occurrence of rainfall at the surface (Sorooshian et al., 2002; Janowiak et al., 2005). Though all MPEs considered here use microwave data, IR contribution appears to dominate the final rainfall product, at least in the case of PERSIANN. On the other hand, MPEs fail to reproduce the weak/insignificant diurnal cycle during the NEM. All MPEs show significant diurnal cycle, albeit with smaller amplitude than in SWM, with a broad peak centered on 15:00 UT. Except during the evening-midnight, the rain rates derived by MPEs and the reference agree fairly well. The overestimation of seasonal rainfall is also probably due to the overestimation of rain intensity during the eveningmidnight period. The overestimation is severe in the case of PERSIANN, similar to that of in the SWM.

\section{Conclusions}

This paper describes the establishment of a dense rain gauge network, its geometric configuration and the quality assurance tests employed to generate high-quality and highresolution rainfall data. The network consists of 36 rain gauges with an intergauge distance of 6-12 km spread over an area of $50 \mathrm{~km} \times 50 \mathrm{~km}$, which makes the network much denser than the operational networks in India. The locations have been chosen to have a near-uniform distribution and consider several practical issues, like accessibility by road, mobile coverage for data transfer and security. The highresolution rainfall measurements have been used to understand the small-scale variability (in space and time) in rain storms and also for validating four widely used MPEs. A suite of statistical error metrics (detection and accuracy) are employed for this purpose. Important results of the analysis are summarized below.

Morphological features of rainfall (like spatial distribution and seasonal rain fraction) are consistent with earlier reports. Though the number of large-scale/long-lived systems (active monsoon spells) is equal in both the seasons, the average duration of each spell is larger during the SWM (6.9 days) than in the NEM (4.4 days). These large-scale systems contribute more than $60 \%$ of seasonal rainfall in the NEM at $3 / 4$ of the locations in the network, whereas the contribution from small-scale/short-lived systems is found to be significant during the SWM (almost equal to that of large-scale systems). The majority of these large-scale/long-lived systems are due to the passage of cyclones during the NEM and due to propagating systems from the west coast during the active monsoon spell in the SWM.

The cumulative distributions for rain duration and intensity (rain accumulation within the storm) show regional differences. These regional differences are more pronounced in the 90th percentile of storm duration and accumulations. The western quadrants experience longer rain duration events with more rain accumulation in the SWM. On the other hand, such events are seen more frequently in northern quadrants during the NEM. While the number and duration of events clearly show a diurnal pattern during the SWM, such pattern is absent in the NEM.

The diurnal cycle exhibits marked seasonal and spatial differences within the study region. The diurnal amplitudes are significant and large during the SWM, while they are insignificant at many locations and also small during the NEM. On average, the diurnal amplitudes are larger during the SWM than those in the NEM by a factor of $\sim 2$. Furthermore, the diurnal cycle explains $70 \%$ of total variance in the SWM, but only $30 \%$ in the NEM. Large diurnal amplitudes are found in western quadrants during the SWM and in eastern quadrants in the NEM. The propagating systems in the SWM appear to be responsible for the observed late nightmidnight peak. During the NEM, the rainfall occurs due to a variety of processes that either do not have any diurnal cycle 
or peak at different times of the day, making the diurnal cycle weak and/or insignificant.

A modified exponential function has been fitted to paired correlations in both seasons for different temporal rainfall accumulations. Clearly, the correlation increases with increasing integration period up to $12 \mathrm{~h}$. However, not much improvement is seen in the correlation with further integration. The correlation falls rapidly when the high-resolution data $(1 \mathrm{~h})$ are employed for the analysis in both monsoon seasons with correlation becoming insignificant after an intergauge distance of $\sim 30 \mathrm{~km}$. Some seasonal differences are seen in the correlation distance, but the differences are not pronounced. The scatter in the correlograms is wide spread along the fitted exponential curve for all accumulation periods in both monsoon seasons, signifying the complex variability of rainfall within the study region.

Comparison of cumulative distributions for MPEs and the reference indicates that all MPEs severely underestimate the weak rain. The MPEs exhibit good detection skills of rain at both 3 and $24 \mathrm{~h}$ resolutions, though considerable improvement is seen with $24 \mathrm{~h}$ resolution data. The FAR values validated at $24 \mathrm{~h}$ resolution are nearly equal to those obtained in earlier studies with a different independent data set (Sunilkumar et al., 2015), indicating the consistency with different data sets. The missing rain is found to be significant at higher resolution in both monsoon seasons. Though the occurrence of missing rain reduced considerably in the SWM at $24 \mathrm{~h}$ resolution, such reduction is absent in the NEM. Possible causes (underestimation of weaker rain and predominance of shallow rain) of the higher occurrence in the NEM are examined. Among various MPEs, the performance of TMPA is found to be poor at $3 \mathrm{~h}$ resolution, but improves tremendously with $24 \mathrm{~h}$ integrated data. CMORPH produces the best $3 \mathrm{~h}$ resolution precipitation products in both monsoon seasons, as evidenced by better accuracy and detection metrics (Table 3).

All MPEs captured the basic shape of the diurnal cycle and the amplitude quite well during the SWM, but they overestimate the rainfall throughout the day. They fail to reproduce the insignificant diurnal cycle during the NEM; rather, MPEs show a significant diurnal cycle in the NEM, albeit with a relatively smaller amplitude.

Acknowledgements. The authors thank various data providers for generating and making them available for research.

Edited by: A. Loew

\section{References}

Adler, R. F., Kidd, C., Petty, G., Morissey, M., and Goodman, H. M.: Intercomparison of global precipitation products: The third precipitation intercomparison project (PIP3), B. Am. Meteorol. Soc., 82, 1377-1396, 2001.
Anderson, T. W.: The Statistical Analysis of Time Series, John Wiley, Hoboken, N.J., 704 pp., 1971.

Aonashi, K., Awaka, J., Hirose, M., Kozu, T., Kubota, T., Liu, G., Shige, S., Kida, S., Seto, S., Takahashi, N., and Takayabu, Y. N.: GSMaP passive microwave precipitation retrieval algorithms: Algorithm description and validation, J. Meteorol. Soc. Jpn., 87A, 119-136, 2009.

Baigorria, A., Jones, J. W., and O'Brien, J. J.: Understanding rainfall spatially variability in southeast USA at different time scales, Int. J. Climatol., 27, 749-760, 2007.

Betts, A. K. and Jacob, C.: Study of diurnal cycle of convective precipitation over Amazonia using a single column model, J. Geophys. Res., 107, 4732, doi:10.1029/2002JD002264, 2002.

Bras, R. L. and Rodriguez-Iturbe, I.: Random functions and Hydrology, Mineola, Dover, New York, 559 pp., 1993.

Chen, Y., Liu, H., An, J., Gorsdorf, U., and Berger, F. H.: A field experiment on the small scale variability of rainfall based on a network of micro rain radars and rain gauges, J. Appl. Meteorol. Clim., 54, 243-255, 2015.

Ciach, G. J. and Krajewski, W. F.: Analysis and modelling of spatial correlation in small scale rainfall in Central Oklahoma, Adv. Water Resour., 29, 1450-1463, 2006.

Dee, D. P., Uppala, S. M., Simmons, A. J., Berrisford, P., Poli, P., Kobayashi, S., Andrae, U., Balmaseda, M. A., Balsamo, G., Bauer, P., Bechtold, P., Beljaars, A. C. M., van de Berg, L., Bidlot, J., Bormann, N., Delsol, C., Dragani, R., Fuentes, M., Geer, A. J., Haimberger, L., Healy, S. B., Hersbach, H., Hólm, E. V., Isaksen, L., Kållberg, P., Köhler, M., Matricardi, M., McNally, A. P., Monge-Sanz, B. M., Morcrette, J.-J., Park, B.-K., Peubey, C., de Rosnay, P., Tavolato, C., Thépaut, J.-N., and Vitart, F. : The ERA-Interim reanalysis: configuration and performance of the data assimilation system, Q. J. Roy. Meteor. Soc., 137, 553597, 2011.

Dinku, T., Connor, S. J., and Ceccato, P.: Comparison of CMORPH and TRMM - 3B42 over mountainous regions of Africa and South America, in: Satellite Rainfall Applications for surface Hydrology, Springer, the Netherlands, 193-204, 2010.

Dzotsi, K. A., Matyas, C. J., Jones, J. W., Baigorria, G., and Hoogenboom, G.: Understanding high resolution space-time variability of rainfall in southwest Georgia, United States, Int. J. Climatol., 34, 3188-3203, 2014.

Ebert, E., Janowiak, J., and Kidd, C.: Comparison of near real time precipitation estimates from satellite observations and numerical models, B. Am. Meteorol. Soc., 88, 47-64, 2007.

Ghajarnia, N., Liaghat, A., and Arsteh, P. D.: Comparison and evaluation of high resolution estimation products in Urmia basinIran, Atmos. Res., 158-159, 50-65, 2015.

Habib, E., Krajewski, F., and Ciach, G. J.: Estimation of rainfall interstation correlation, J. Hydrometeorol., 2, 621-629, 2001.

Habib, E., Henschke, A., and Adler, R. F.: Evaluation of TMPA satellite-based research and real-time rainfall estimates during six tropical-related heavy rainfall events over Louisiana, USA, Atmos. Res., 3, 373-388, 2009.

Habib, E., Haile, A., Tian, Y., and Joyce, R. J.: Evaluation of the high-resolution CMORPH satellite rainfall product using dense rain gauge observations and radar-based estimates, J. Hydrometeorol., 13, 1784-1798, 2012. 
Houze Jr., R. A., Wilton, D. C., and Smull, B. F.: Monsoon convection in the Himalayan region as seen by the TRMM precipitation radar, Q. J. Roy. Meteor. Soc., 133, 1389-1411, 2007.

Hsu, K. L., Gao, X., Sorooshian, S., and Gupta, H. V.: Precipitation estimation from remotely sensed information using artificial neural networks, J. Appl. Meteorol., 36, 1176-1190, 1997.

Huffman, G. J., Adler, R. F., Bolvin, D. T., Gu, G., Nelkin, E. J., Bowman, K. P., Hong, Y., Stocker, E. F., and Wolf, D. B.: The TRMM multi satellite precipitation analysis (TMPA): quasi global, multiyear, combined sensor precipitation estimates at finer scales, J. Hydrometeorol., 8, 38-55, 2007.

Janowiak, J. E., Kousky, V. E., and Joyce, R. J.: Diurnal cycle of precipitation determined from the CMORPH high spatial and temporal resolution global precipitation analyses, J. Geophys. Res., 110, D23105, doi:10.1029/2005JD006156, 2005.

Joyce, R. J., Janowiak, J., Arkin, P., and Xie, P.: CMORPH: A method that produces global precipitation estimates from passive microwave and infrared data at high spatial and temporal resolutions, J. Hydrometeorol., 5, 487-503, 2004.

Kidd, C., Levizzani, V., Turk, J., and Ferraro, R.: Satellite precipitation measurements for water resources monitoring, J. Am. Water Resour. As., 45, 567-579, 2009.

Kidd, C., Bauer, P., Turk, J., Huffman, G. J., Joyce, R., Hsu, K. L., and Braithwaite, D.: Intercomparison of high-resolution precipitation products over Northwest Europe, J. Hydrometeorol., 13, 67-83, 2012.

Kikuchi, K. and Wang, B.: Diurnal precipitation regimes in the global tropics, J. Climate, 21, 2680-2696, 2008.

Krajewski, W. F., Ciach, G. J., and Habib, E.: An analysis of small scale variability in different climatic regimes, Hydrolog. Sci. J., 48, 151-162, 2003.

Kubota, T., Shinge, S., Hashizume, H., Aonashi, K., Takahashi, N., Seto, S., Hirose, M., Takayabu, Y. N., Nakagawa, K., Iwaanami, K., Ushio, T., Kachi, M., and Okamato, K.: Global Precipitation Map using Satellite borne Microwave Radiometers by the GSMaP Project: Production and validation, IEEE T. Geosci. Remote, 45, 2259-2275, 2007.

Kucera, P. A., Ebert, E. E., Turk, F. J., Levizzani, V., Kirschbaum, D., Tapiador, F. J., Loew, A., and Borsche, M.: Precipitation from space advancing earth system science, B. Am. Meteorol. Soc., 365-375, doi:10.1175/BAMS-D-11-00171.1, 2013.

Levizzani, V., Bauer, P., and Turk, F. J.: Measuring precipitation from space, Springer, the Netherlands, doi:10.1007/978-1-40205835-6, 722 pp., 2007.

Li, L., Hong, Y., Wang, J., Adler, R. F., Policelli, F. S., Habib, S., Irwn, D., Korme, T., and Okello, L.: Evaluation of the real-time TRMM -based multi-satellite precipitation analysis for an operational flood prediction systems in Nzoia basin, Lake Victoria, Africa, Nat. Hazards, 50, 109-123, 2009.

Li, Z., Yang, D., Hong, Y., Zhang, J., and Qi, Y.: Characterizing spatiotemporal variations of hourly rainfall by gauge and radar in the mountainous three Gorges region, J. Appl. Meteorol. Clim., 53, 873-889, 2014.

Cohen Liechti, T., Matos, J. P., Boillat, J.-L., and Schleiss, A. J.: Comparison and evaluation of satellite derived precipitation products for hydrological modeling of the Zambezi River Basin, Hydrol. Earth Syst. Sci., 16, 489-500, doi:10.5194/hess-16-4892012, 2012.
Luini, L. and Capsoni, C.: The impact of space and time averaging on the spatial correlation of rainfall, Radio Sci., 47, RS3013, doi:10.1029/2011RS004915, 2012.

Mandapaka, P. V. and Qin, X.: Analysis and characterization of probability distribution and small scale variability of rainfall in Singapore using a dense gauge network, J. Appl. Meteorol. Clim., 52, 2781-2796, 2013.

Mehran, A. and AghaKouchak, A.: Capabilities of satellite precipitation datasets to estimate heavy precipitation rates at different temporal accumulations, Hydrol. Process., 28, 2262-2270, 2014.

Mohan, T.: Characteristics of wet and dry spells during southwest monsoon season over southeast India-a diagnostic study, Dept. of Meteorology and oceanography, Andhra University, Visakhapatnam, India, 2011.

Nesbitt, S. W. and Zipser, E. J.: The diurnal cycle of rainfall and convective intensity according to three years of TRMM measurements, J. Climate, 16, 1456-1475, 2003.

Nešpor, V. and Sevruk, B.: Estimation of wind-induced error of rainfall gauge measurements using a numerical simulation, J. Atmos. Ocean. Tech., 16, 450-464, 1999.

Prakash, S., Sathiyamoorthy, V., Mahesh, C., and Gairola, R. M.: An evaluation of high-resolution multisatellite products over the Indian monsoon region, Int. J. Remote Sens., 35, 3018-3035, 2014.

Prat, O. P. and Nelson, B. R.: Evaluation of precipitation estimates over CONUS derived from satellite, radar, and rain gauge data sets at daily to annual scales (2002-2012), Hydrol. Earth Syst. Sci., 19, 2037-2056, doi:10.5194/hess-19-2037-2015, 2015.

Radhakrishna, B., Rao, T. N., Rao, D. N., Rao, N. P., Nakamura, K., and Sharma, A. K.: Spatial and seasonal variability of raindrop size distributions in southeast India, J. Geophys. Res., 114, D04203, doi:10.1029/2008JD011226, 2008.

Rahman, S. H., Sengupta, D., and Ravichandran, M.: Variability of Indian summer monsoon rainfall in daily data from gauge and satellite, J. Geophys. Res., 114, D17113, doi:10.1029/2008JD011694, 2009.

Rajeevan, M., Bhate, J., Kale, K. D., and Lal, B.: High resolution daily gridded rainfall data for the Indian region: Analysis of break and active monsoon spells, Curr. Sci., 91, 296-306, 2006.

Raju, G.: Engineering challenges in the Megha-Tropiques satellite, Curr. Sci. India, 104, 1662-1670, 2013.

Rao, T. N., Rao, D. N., Mohan, K., and Raghavan, S.: Classification of tropical precipitating systems and associated Z-R relationships, J. Geophys. Res., 106, 17699-17712, 2001.

Rao, T. N., Radhakrishna, B., Nakamura, K., and Prabhakara Rao, N.: Differences in raindrop size distribution from southwest monsoon to northeast monsoon at Gadanki, Q. J. Roy. Meteor. Soc., 135, 1630-1637, 2009.

Roca, R., Brogniez, H., Chambon, P., Chomette, O., Cloche, S., Gosset, M. E., Mahfouf, J.-F., Raberanto, P., and Viltard, N.: The Megha-Tropiques mission: a review after three years in orbit, Front. Earth Sci., 3, 1-14, doi:10.3389/feart.2015.00017, 2015.

Saikranthi, K., Rao, T. N., Radhakrishna, B., and Rao, S. V. B.: Morphology of the vertical structure of precipitation over India and adjoining oceans based on the long-term measurements of TRMM PR, J. Geophys. Res., 119, 8433-8449, 2014.

Sapiano, M. R. P. and Arkin, P. A.: An intercomparison and validation of high-resolution satellite precipitation estimates with 3-hourly gauge data, J. Hydrometeorol., 10, 149-166, 2009. 
Simpson, M., Warrior, H., Raman, S., Aswathanarayana, P. A., Mohanty, U. C., and Suresh, R.: Sea breeze Initiated Rainfall over the East Coast of India during the Indian Southwest Monsoon, Nat. Hazards, 42, 401-413, 2007.

Sohn, B. J., Jin-Han, H., and Seo, E.: Validation of satellite-based high resolution rainfall over the Korean Peninsula using data from a dense rain gauge network, J. Appl. Meteorol. Clim., 49, 701-714, 2010.

Sorooshian, S., Hsu, K., Gao, X., Gupta, H. V., Imam, B., and Braithwaite, D.: Evaluation of PERSIANN system satellitebased estimates of tropical rainfall, B. Am. Meteorol. Soc., 81, 2035-2046, 2000.

Sorooshian, S., Gao, X., Hsu, K., Maddox, R. A., Hong, Y., Gupta, H. V., and Imam, B.: Diurnal variability of tropical rainfall retrieved from combined GOES and TRMM satellite information, J. Climate, 15, 983-1001, 2002.

Sunilkumar, K., Rao, T. N., Saikranthi, K., and Rao, M. P.: Comprehensive evaluation of multisatellite precipitation estimates over India using high-resolution gridded rainfall data, J. Geophys. Res., 120, 8987-9005, doi:10.1002/2015JD023437, 2015.

Tian, Y., Lidard, C. D. P., Choudhury, C. B. J., and Garcia, M.: Multitemporal analysis of TRMM-based satellite precipitation products for land data assimilation application, J. Hydrometeorol., 8, 1165-1183, 2007.

Tokay, A. and Ozturk, K.: An experimental study of spatial variability of rainfall, J. Hydrometeorol., 15, 801-812, 2012.

Tokay, A., Roche R. J., and Bashor, P. J.: An experimental study of the small-scale variability of rainfall, J. Hydrometeorol., 13, 351-365, 2014.
Turk, F. J., Arkin, P., Sapiano, M. R. P., and Ebert, E. E.: Evaluating high-resolution precipitation products, B. Am. Meteorol. Soc., 89, 1911-1916, 2008.

Uma, R., Kumar, T. V. L., Narayanan, M. S., Rajeevan, M., Bhate, J., and Niranjan Kumar, K.: Large scale features and assessment of spatial scale correspondence between TMPA and IMD rainfall datasets over Indian landmass, J. Earth Syst. Sci., 122, 573-588, 2013.

Villarini, G., Mandapaka, P. V., Krajewski, W. F., and Moore, R. J.: Rainfall and sampling uncertainities: A rain gauge perspective, $\mathrm{J}$. Geophys. Res., 113, D11102, doi:10.1029/2007JD009214, 2008

Wang, N.-Y., Liu, C., Ferraro, R., Wolff, D., Zipser, E., and Kummerow, C.: TRMM 2A12 land precipitation product - status and future plans, J. Meteorol. Soc. Jpn., 87A, 237-253, 2009.

Weisman, M. L. and Rotunno, R.: A theory for strong long-lived squall lines revisited, J. Atmos. Sci., 61, 361-382, 2004.

World Meteorological Organization (WMO): Guide to meteorological instruments and methods of observation, WMO-No.8, Seventh edition, Geneva, 2008.

Yang, S. and Smith, E. A.: Mechanisms for diurnal variability of global tropical rainfall observed from TRMM, J. Climate, 19, 5190-5226. 2006.

Zängl, G.: Interaction between dynamics and cloud microphysics in orographic precipitation enhancement: A modelling study of two North Alapine heavy-precipitation events, Mon. Weather Rev., $135,2817-2840,2007$ 